\title{
An Accurate Wide-speed Range Control Method of IPMSM Considering Resistive Voltage Drop and Magnetic Saturation
}

\author{
Shuo Wang ${ }^{1}$, Member, Jinsong $\mathrm{Kang}^{1}$, Member, Michele Degano ${ }^{2,3}$, Member, Alessandro \\ Galassini $^{2}$, Member and Chris Gerada ${ }^{2,3}$, Senior Member
}

\begin{abstract}
This paper deals with the high accurate current set-points solution for Interior Permanent-Magnet Synchronous Motors (IPMSM) in wide-speed range applications. Considering voltage and current constraints, the operating regions can be divided into Maximum Torque Per Ampere (MTPA), Maximum Current (MC), Field Weakening (FW) and Maximum Torque Per Voltage (MTPV) regions, which requires to solve different non-linear functions in real time to obtain optimal current set-points. Traditional methods including curve-fitting methods and polynomial approximation (PA) methods are not easy to obtain these solutions, especially involving magnetic saturation problems. In this paper, Newton- Raphson (N-R) algorithm for improving the control accuracy of the current set-points is proposed. Meanwhile, parameters influence including magnetic saturation and resistive voltage drop is fully investigated. Compared with PA method, the proposed method is able to converge to accurate solutions in few numbers of iterations with reduced execution time, which can be easily implemented on an off-the-shelf Digital Signal Processor (DSP). Both simulation results and experimental results on an 8kW IPMSM rig are conducted showing good agreement with the expected results.
\end{abstract}

Index Terms-Cross Saturation, flux-weakening control, interior permanent-magnet synchronous motors (IPMSM), magnetic Saturation, Newton-Raphson (N-R) method, resistive voltage drop

\section{INTRODUCTION}

$\mathrm{I}^{\mathrm{I}}$ nterior Permanent Magnet Synchronous Motors (IPMSM) 1 are widely used in industrial applications such as in hybrid and electric vehicles, thanks to their high efficiency, wide speed range and power density capabilities. In some applications such

Manuscript received October 10, 2018; revised December 19, 2018; accepted March 26, 2019. This work was supported in part by National Key Research and Development Program of China under Grant 2016YFB1200602-02.

S. Wang and J. Kang are with the College of Electronic and Information Engineering, Tongji University, Shanghai 201804, China (email:wangshuo-27@163.com; kjs@tongji.edu.cn).

M. Degano, A. Galassini and C. Gerada are with the Power Electronics, Machines and Control Group (PEMC Group), the University of Nottingham, Nottingham, NG7 2RD, UK (e-mail: michele.degano@nottingham.ac.uk;alessandro.galassini@nottingham. ac.uk; chris.gerada @nottingham.ac.uk).

M. Degano and C. Gerada are also with the PEMC Group the University of Nottingham Ningbo China, Ningbo 315100, China. as electric vehicles, where a wider speed range is required, the operating regions of an IPMSM needs to be extended from constant-torque region to constant-power region ${ }^{[1][2]}$. In general, the operating conditions can be summarized in four regions: Maximum Torque Per Ampere (MTPA), Maximum Current (MC), Field Weakening (FW), and Maximum Torque Per Voltage (MTPV).

When the motor is operating under the base speed, the maximum torque per ampere (MTPA), which aims at minimising the copper loss, becomes more attractive. The works proposing MTPA control strategies can be mainly divided into three categories: 1) Mathematical-model-based MTPA calculations $^{[3][4]}$; 2) Signal injection-based MTPA point tracking $^{[5]-[8]}$; 3) Searching-method-based MTPA ${ }^{[9][10]}$. First methods including curve-fitting ${ }^{[3]}$ and polynomial approximation $^{[4]}$, are proposed to solve nonlinear MTPA formula directly. However, inductance is regarded as linear variation with current and cross-saturation effect is ignored. Second methods utilized high frequency current injections ${ }^{[5][6]}$ or voltage injections ${ }^{[8]}$, MTPA points can be detected either from the torque or the speed response. However, the injected current signals may result in torque ripple problems. Third methods, aiming at minimising copper losses, present gradient method in [9][10]. However, most of the time, the variation of inductances with respect to the current is neglected for computation and implementation simplicity.

When the speed of IPMSM goes up above base speed in MC region and FW region, the flux-weakening methods are needed, presented in [11]-[16]. Defined by the way to acquire more negative d-axis current, two approaches for implementing the flux-weakening control are presented as feedforward ${ }^{[11]-[14]}$ and feedback ${ }^{[15]-[17]}$ methods. In the feedforward approaches [11][14], the intersections (solutions) involving current circle, voltage ellipse and torque hyperbola requires solving complex nonlinear equations online. To simplify the solving process, resistive voltage drop and magnetic saturation are often neglected[3][11], which loses the accuracy of the current setpoints. The resistive voltage drop, which causes the voltage ellipse shifting, can be compensated from control part in [11] or from calculation part using "Chord method" proposed in [12][14]. In the feedback approaches ${ }^{[15]-[17]}$, the negative d-axis current is automatically adjusted by tracking the voltage 
constraint while the speed is increasing. These methods are considered robust because they do not need the prior knowledge of motor parameters, but this is at the expense of reduced performance during transients ${ }^{[17]}$. When the motor is operating in deep flux-weakening region, so-called MTPV region mentioned in [18]-[20], the MTPV is the intersection of the voltage ellipses with the highest torque hyperbola at saturated stator voltage. The common method proposed in [19] and [20] are mathematical model-based MTPV calculations. The same problems are parametric sensitive.

All aforementioned open loop methods have an advantage on high dynamic response. However, in most of cases, the variation of inductances with respect to the current is neglected for computation simplicity. In fact, there are always some parameters uncertainties including inductance variations and permanent magnetic linkage variations ${ }^{\text {[21]-[26] }}$. Two common solutions including PA methods and parameter identification methods are investigated in related works. The former one applies PA methods for curve-fitting, such as first-order PA method in [21][22]. The inductance is considered linear variation with current. However, cross-saturation is ignored. The second-order PA methods, to achieve inductance approximation, are introduced to obtain MTPA and FW curves, which makes the curves a fourth order complicate nonlinear equations, discussed in [23]-[25]. The latter one such as PSO (Particle Swarm Optimization) are presented in [27]-[29], the identification results are compared with experimental results obtained by current decay test. The experimental accuracy is also key issue for practical use.

Nevertheless, to the best knowledge of the authors, a complete theory, which (a) covers all operation regions (such as MTPA, MC, FW, MTPV) ,(b) allows for an analytical computation of optimal currents set-points, (c) considers stator resistance and variable inductance, is not yet available.

In this paper, a novel and accurate feedforward NewtonRaphson searching method in all operating regions is proposed, while taking into account both the resistive voltage drop and the magnetic saturation. The proposed method is characterized by the following:(a) Analysis of all the operating regions (MTPA, MC, FW, MTPV); (b) Implicit problem formulation (the nonlinear solutions involving current circle, voltage ellipse and torque hyperbola); (c) Real-time implementation on a digital microcontroller with few iterations and reduced computation burdens. Both simulation and experimental results under different conditions prove the effectiveness and rapidity of the proposed methods.

The paper is organized as follows: in Section II, the different operation modes for IPMSM are described. In Section III, the proposed N-R searching method is elaborated. The influence of resistive voltage drop and magnetic saturation is explained in Section IV. Simulation and experimental results are presented in Section V and Section VI respectively. Conclusions are given in Section VII.

\section{ANALYSIS OF OPERATING MODES FOR IPMSM}

In this Section, the operating loci introduced in the introduction are extended and described by mean of analytical equations and figures. Within the rotating reference frame, the equations for an IPMSM can be written as follows:

$$
\begin{gathered}
\left\{\begin{array}{l}
u_{d}=R_{s} i_{d}+\frac{d \psi_{d}}{d t}-\omega_{e} \psi_{q} \\
u_{q}=R_{s} i_{q}+\frac{d \psi_{q}}{d t}+\omega_{e} \psi_{d}
\end{array}\right. \\
\left\{\begin{array}{l}
\psi_{d}=L_{d} i_{d}+\psi_{f} \\
\psi_{q}=L_{q} i_{q}
\end{array}\right.
\end{gathered}
$$

Where, $u_{\mathrm{d}}$ and $u_{\mathrm{q}}$ are the $\mathrm{d}$-q-axis stator voltages; $i_{\mathrm{d}}$ and $i_{\mathrm{q}}$ are dq-axis current; $L_{\mathrm{d}}$ and $L_{\mathrm{q}}$ are the dq-axis inductance, $R_{\mathrm{s}}, \psi_{\mathrm{f}}, p$ are the stator resistance, the permanent-magnet flux linkage and the pole pairs, respectively. $\omega_{\mathrm{e}}$ is the electrical angular frequency.

There are also two additional constraints to be taken into account. The first one is related to the current constraints of the motor or the inverter (3). The second one is related to the voltage constraints (4).

$$
\begin{aligned}
& i_{d}^{2}+i_{q}^{2} \leq I_{\max , \mathrm{pk}}^{2} \\
& u_{d}^{2}+u_{q}^{2} \leq U_{\max }^{2}
\end{aligned}
$$

where $U_{\max }\left(U_{\mathrm{dc}} / \sqrt{3}\right)$ is the maximum voltage for SVPWM.
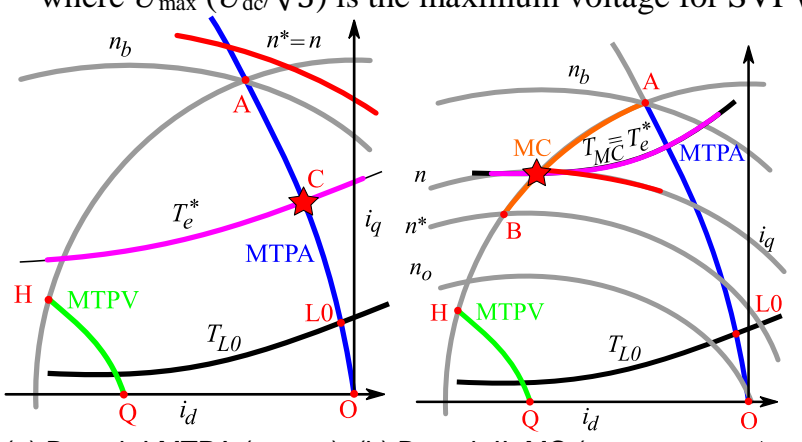

(a) Branch I:MTPA $\left(\mathrm{n} \leq \mathrm{n}_{\mathrm{b}}\right)$ (b) Branch II: MC $\left(\mathrm{n}_{\mathrm{b}}<\mathrm{n} \leq \mathrm{n}_{\mathrm{o}}, \mathrm{T}_{e}^{*} \geq \mathrm{T}_{\mathrm{MC}}\right)$

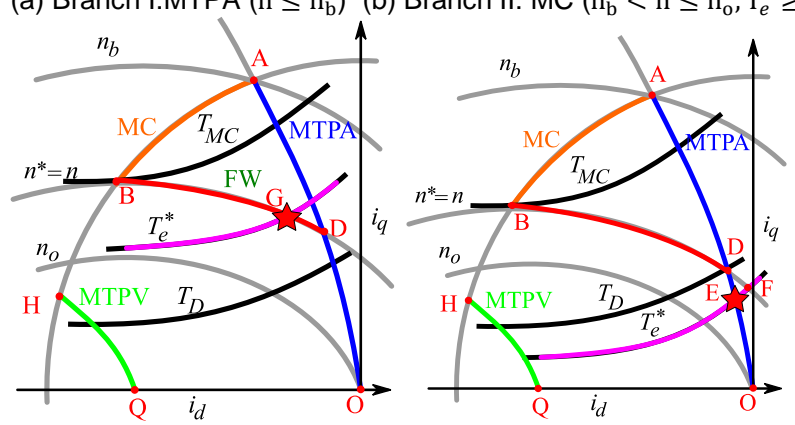

(c) Branch II: FW ( $\mathrm{n}_{\mathrm{b}}<\mathrm{n} \leq \mathrm{n}_{\mathrm{o}}, \mathrm{T}_{\mathrm{D}}<\mathrm{T}_{e}^{*}<\mathrm{T}_{\mathrm{MC}}$ ) (d) Branch II MTPA: $\left(\mathrm{n}_{\mathrm{b}}<\right.$ $\left.\mathrm{n} \leq \mathrm{n}_{\mathrm{o}}, \mathrm{T}_{e}^{*} \leq \mathrm{T}_{\mathrm{D}}\right)$
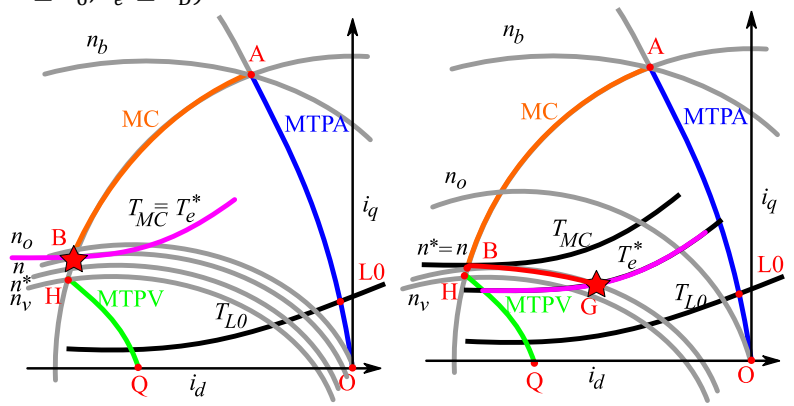

(e) Branch III:MC $\left(\mathrm{n}_{\mathrm{o}}<\mathrm{n} \leq \mathrm{n}_{\mathrm{v}}, \mathrm{T}_{e}^{*} \geq \mathrm{T}_{\mathrm{MC}}\right)$ (f) Branch III:FW ( $\mathrm{n}_{\mathrm{o}}<\mathrm{n} \leq$ $\left.\mathrm{n}_{\mathrm{v}}, \mathrm{T}_{e}^{*}<\mathrm{T}_{\mathrm{MC}}\right)$ 

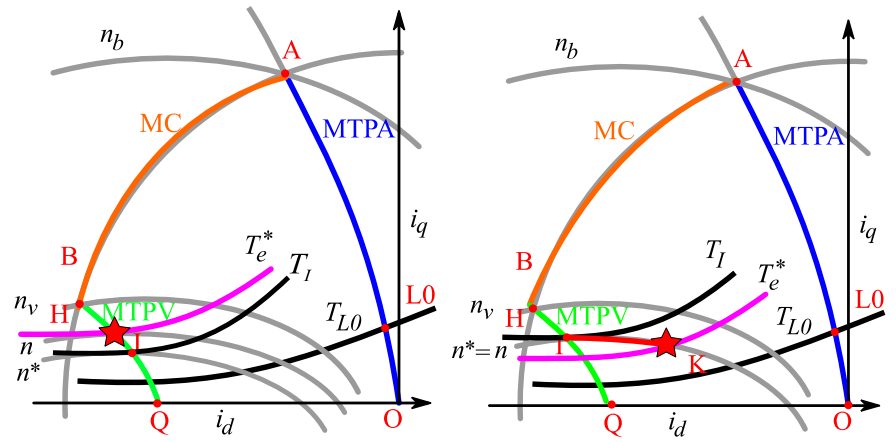

(g) Branch IV:MTPV $\left(\mathrm{n} \geq \mathrm{n}_{\mathrm{v}}, \mathrm{T}_{e}^{*} \geq \mathrm{T}_{\mathrm{I}}\right)$ (h) Branch IV:FW ( $\left.\mathrm{n} \geq \mathrm{n}_{\mathrm{v}}, \mathrm{T}_{e}^{*}<\mathrm{T}_{\mathrm{I}}\right)$ Fig.1 The operating modes in the dq-axis current plane

As can be seen in (3), the current constraints trajectory in the dq-axis forms a circle (curve AH in Fig.1), whose center is the origin and the radius is $I_{\max , p k}$. Substituting (1) and (2) into (3), and neglecting the resistance drop, (4) can be rewritten as the following:

$$
\left(-\omega_{e} L_{q} i_{q}\right)^{2}+\left(\omega_{e} L_{d} i_{d}+\omega_{e} \psi_{f}\right)^{2} \leq\left(U_{d c} / \sqrt{3}\right)^{2}
$$

Equation (5) describes the iso-voltage constraints ellipse shrunk with the increasing speed in the dq-axis current plane, whose center $\mathrm{Q}$ is $\left(-\psi_{\mathrm{f}} / L_{\mathrm{d}}, 0\right)$. The electromagnetic torque is given by the following equation:

$$
T_{e}=\frac{3}{2} p\left[\psi_{f} i_{q}+\left(L_{d}-L_{q}\right) i_{d} i_{q}\right]
$$

The effective operating regions are shown in Fig.1, which consists of MTPA region (curve OA), MC region (curve AH), FW region (area OAHQ) and MTPV region (curve $H Q$ ). Defining superscript * as any generic set-point, $T_{e}^{*}$ is the torque set-point, which at steady state is equal to the load torque $T_{\mathrm{L}} \cdot n^{*}$ is the speed set-point, $\mathrm{n}$ is the measured speed, $n_{\mathrm{b}}$ is the base speed, $n_{\text {max }}$ is the maximum speed defined by the mechanic components (i.e. shaft, bearings, etc.), and $\mathrm{n}_{o}$ is the boundary speed defined by the iso-voltage constraint ellipse passing through the origin. $\mathrm{n}_{v}$ is the deep-flux-weakening speed defined by iso-voltage constraint ellipse passing through the intersection of MTPV locus and current circle (point $\mathrm{H}$ in Fig. 2(g)). Defining also $T_{\mathrm{L} 0}$ as the torque hyperbola at no load, $T_{\mathrm{D}}$ as the cut-off torque identified by the intersection of the MTPA locus with the iso-voltage ellipse at speed set-points (point D in Fig.1(c) and Fig.1(d)), $T_{\mathrm{I}}$ as the cut-off torque identified by the intersection of the MTPV locus with the iso-voltage ellipse at speed set-points (point I in Fig. 1(g) and Fig.1(h)), and $T_{\mathrm{MC}}$ as the maximum torque for a measured speed in MC region.

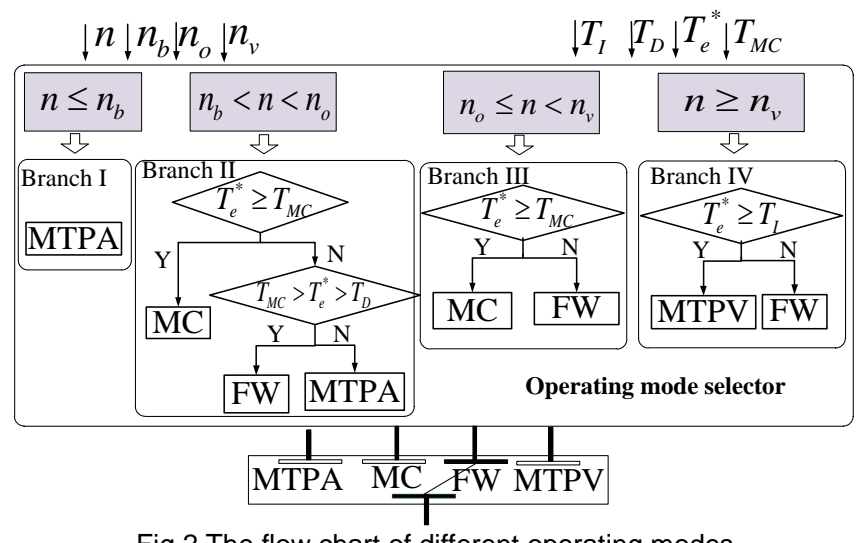

Fig.2 The flow chart of different operating modes
The operating mode selector provides the right mode taken into account together with the proposed Newton-Raphson searching method explained in Section. III, which presents four main branches selecting one mode among the following ones: MTPA, MC, FW and MTPV. The relationship for speed and the torque is explained in the following paragraphs with aid of Fig. 1 and Fig. 2. In the following paragraphs, the four branches are described as follows:

Branch I $\left(n \leq n_{\mathrm{b}}\right)$

In this branch, the speed $n$ is lower than the base speed $n_{\mathrm{b}}$ and the IPMSM is operating on the MTPA curve OA, shown in Fig.1(a). The red star is the steady operating point $\mathrm{C}$ and it is defined by the intersection of the MTPA and the load torque curves. The MTPA solution is formulated as (7) aiming at copper loss minimization problem:

$$
\begin{cases}\min & R_{s}\left(i_{d}^{* 2}+i_{q}^{* 2}\right) \\ \text { s.t. } & T_{e}^{*}=1.5 \mathrm{p}\left[\psi_{f} i_{q}^{*}+\left(L_{d}-L_{q}\right) i_{q}^{*} i_{d}^{*}\right]\end{cases}
$$

The Lagrange multiplier is applied to obtain the solution:

$$
H\left(i_{d}, i_{q}, \lambda\right)=R_{s}\left(i_{d}^{* 2}+i_{q}^{* 2}\right)+\lambda\left[T_{e}^{*}-1.5 p\left(\psi_{f} i_{q}^{*}+\left(L_{d}-L_{q}\right) i_{q}^{*} i_{d}^{*}\right)\right]
$$

The partial derivative of (8) is obtained as (9):

$$
\left\{\begin{array}{l}
\frac{\partial H\left(i_{d}^{*}, i_{q}^{*}, \lambda\right)}{\partial i_{d}^{*}}=2 R_{s} i_{d}^{*}-\lambda \frac{3}{2} \mathrm{p}\left(L_{d}-L_{q}\right) i_{q}^{*}=0 \\
\frac{\partial H\left(i_{d}^{*}, i_{q}^{*}, \lambda\right)}{\partial i_{q}^{*}}=2 R_{s} i_{q}^{*}-\lambda \frac{3}{2} \mathrm{p}\left(\psi_{f}+\left(L_{d}-L_{q}\right) i_{d}^{*}\right)=0 \\
\frac{\partial H\left(i_{d}, i_{q}, \lambda\right)}{\partial \lambda}=T_{e}^{*}-\frac{3}{2} p\left(\psi_{f} i_{q}^{*}+\left(L_{d}-L_{q}\right) i_{d}^{*} i_{q}^{*}\right)=0
\end{array}\right.
$$

Solving the first two equations in (9) by eliminating the parameter $\lambda$, the MTPA relationship for dq-axis currents can be expressed as (10):

$$
\operatorname{MTPA}\left\{\begin{array}{l}
T_{e}^{*}=1.5 \mathrm{p}\left[\psi_{f} i_{q}^{*}+\left(L_{d}-L_{q}\right) i_{q}^{*} i_{d}^{*}\right] \\
\left(L_{d}-L_{q}\right) i_{d}^{* 2}-\left(L_{d}-L_{q}\right) i_{q}^{* 2}+\psi_{f} i_{d}^{*}=0
\end{array}\right.
$$

Branch II: $\left(n_{b}<n \leq n_{o}\right)$

If the speed $n$ is higher than base speed $n_{\mathrm{b}}$ and less than the boundary speed $n_{\mathrm{o}}$, voltage constraint ellipse shrinks to point A. More negative d-axis current is needed to make the dq-axis current set-points move along MC circle along curve AB shown in Fig.1(b), limited by both voltage constraint and current constraint, which can be expressed in (11). $T_{M C}$ can be calculated at the same time in (11):

$$
M C\left\{\begin{array}{l}
i_{d}^{* 2}+i_{q}^{* 2}=I_{\max }^{2} \\
\left(\omega_{e} L_{q} i_{q}^{*}\right)^{2}+\left(\omega_{e} L_{d} i_{d}^{*}+\omega_{e} \psi_{f}\right)^{2}=\left(\frac{U_{d c}}{\sqrt{3}}\right)^{2} \\
T_{M C}=\frac{3}{2} p\left[\psi_{f} i_{q}^{*}+\left(L_{d}-L_{q}\right) i_{d}^{*} i_{q}^{*}\right]
\end{array}\right.
$$

When the measured speed $n$ is approaching the speed setpoint $n^{*}$ and if the condition $T_{D}<T_{e}^{*}<T_{M C}$ is satisfied, the dqaxis current set-point will move along the voltage ellipse curve $\mathrm{BD}$ towards point $\mathrm{G}$ in FW region shown in Fig.1(c). Point D is the voltage constraint ellipse at speed set-point $n^{*}$ intersected with MTPA curve marked in Fig.1(c) and Fig.1(d). $T_{D}$ can be calculated in (12) and the first equation in (12) comes from (10): 


$$
\left\{\begin{array}{l}
\left(L_{d}-L_{q}\right) i_{d}^{* 2}-\left(L_{d}-L_{q}\right) i_{q}^{* 2}+\psi_{f} i_{d}^{*}=0 \\
\omega_{e}^{*}=\frac{\pi \cdot p \cdot n^{*}}{30} \\
\left(\omega_{e}^{*} L_{q} i_{q}^{*}\right)^{2}+\left(\omega_{e}^{*} L_{d} i_{d}^{*}+\omega_{e}^{*} \psi_{f}\right)^{2}=\left(\frac{U_{d c}}{\sqrt{3}}\right)^{2} \\
T_{D}=\frac{3}{2} p\left[\psi_{f} i_{q}^{*}+\left(L_{d}-L_{q}\right) i_{d}^{*} i_{q}^{*}\right]
\end{array}\right.
$$

In this case, the dq-axis current set-points are limited by both torque hyperbola and voltage constraint expressed in (13):

$$
\mathrm{FW}\left\{\begin{array}{l}
T_{e}^{*}=1.5 \mathrm{p}\left[\psi_{f} i_{q}^{*}+\left(L_{d}-L_{q}\right) i_{q}^{*} i_{d}^{*}\right] \\
\left(\omega_{e} L_{q} i_{q}^{*}\right)^{2}+\left(\omega_{e} L_{d} i_{d}^{*}+\omega_{e} \psi_{f}\right)^{2}=\left(\frac{U_{d c}}{\sqrt{3}}\right)^{2}
\end{array}\right.
$$

If the condition $\mathrm{T}_{\mathrm{e}}^{*}<\mathrm{T}_{\mathrm{D}}$ is satisfied, the point $\mathrm{F}$, the intersection between voltage constraints ellipse and the load torque curve, is located outside the top left quadrant, the final operating point can't go across the boundary MTPA curve OA and finally it settles at point E, shown in Fig.1(d). Curve DE is part of MTPA curve can be expressed as (10) as well.

Branch III: $\left(n_{o}<n \leq n_{v}\right)$

When the measured speed is higher than $n_{o}$ and if the measured speed $n$ is approaching the set-point speed $n^{*}$, The dq-axis current set-point will move along the MC circle shown in Fig.1(e). In this case, the dq-axis current set-point is limited by both current constraint and voltage constraint can be expressed in (11). If the condition $\mathrm{T}_{e}^{*} \leq \mathrm{T}_{\mathrm{MC}}$ is satisfied, the dqaxis current set-point will move along the voltage ellipse at speed $n^{*}$ curve BD and balance at point G shown in Fig.1(f), as can be expressed as (13) as well.

Branch IV: $\left(n_{v} \leq n<n_{\max }\right)$

When the measured speed is higher than $n_{v}$ (iso-voltage constraint ellipse passing through the intersection of MTPV locus and current circle), the motor is operating in MTPV region (deep flux-weakening region). If the measured speed $n$ is lower than the set-point speed $n^{*}$, The dq-axis current setpoint will move along the MTPV curve shown in Fig.1(g). MTPV solution is formulated as (14) aiming at output power minimization:

$$
\begin{cases}\min & u_{d} i_{d}^{*}+u_{q} i_{q}^{*} \rightarrow \frac{d\left(u_{d} i_{d}^{*}+u_{q} i_{q}^{*}\right)}{d i_{d}^{*}}=0 \\ \text { s.t. } & \left(\omega_{e} L_{q} i_{q}^{*}\right)^{2}+\left(\omega_{e} L_{d} i_{d}^{*}+\omega_{e} \psi_{f}\right)^{2}=\left(\frac{U_{d c}}{\sqrt{3}}\right)^{2}\end{cases}
$$

Solving (14), the MTPV relationship for dq-axis currents can be expressed as first equation in (15). In this MTPV mode, the dq-axis current set-point is limited by both MTPV curve and voltage constraint:

$$
\operatorname{MTPV}\left\{\begin{array}{l}
\left(L_{q} i_{q}^{*}\right)^{2}\left(L_{d}-L_{q}\right)-\psi_{f} L_{q}\left(L_{d} i_{d}^{*}+\psi_{f}\right)-\left(L_{d}-L_{q}\right)\left(L_{d} i_{d}^{*}+\psi_{f}\right)^{2}=0 \\
\left(\omega_{e} L_{q} i_{q}^{*}\right)^{2}+\left(\omega_{e} L_{d} i_{d}^{*}+\omega_{e} \psi_{f}\right)^{2}=\left(\frac{U_{d c}}{\sqrt{3}}\right)^{2}
\end{array}\right.
$$

If the condition $\mathrm{T}_{e}^{*}<\mathrm{T}_{\mathrm{I}}$ is satisfied, the dq-axis current setpoint will move along the voltage ellipse at speed $n^{*}$ (curve IK) and balance with the load torque (point K) shown in Fig.2(h), as can be expressed as (13) as well.

$T_{I}$ is cut-off torque, identified by the intersection of the
MTPV locus with the iso-voltage ellipse at speed set-points. $T_{I}$ can be calculated in (16). The first equation of (16) comes from MTPV solution (15):

$$
\left\{\begin{array}{l}
\left(L_{q} i_{q}^{*}\right)^{2}\left(L_{d}-L_{q}\right)-\psi_{f} L_{q}\left(L_{d} i_{d}^{*}+\psi_{f}\right)-\left(L_{d}-L_{q}\right)\left(L_{d} i_{d}^{*}+\psi_{f}\right)^{2}=0 \\
\omega_{e}^{*}=\frac{\pi \cdot p \cdot n^{*}}{30} \\
\left(\omega_{e}^{*} L_{q} i_{q}^{*}\right)^{2}+\left(\omega_{e}^{*} L_{d} i_{d}^{*}+\omega_{e}^{*} \psi_{f}\right)^{2}=\left(\frac{U_{d c}}{\sqrt{3}}\right)^{2} \\
T_{I}=\frac{3}{2} p\left[\psi_{f} i_{q}^{*}+\left(L_{d}-L_{q}\right) i_{d}^{*} i_{q}^{*}\right]
\end{array}\right.
$$

The challenge in solving (10)-(16) is discussed below:

1) The solutions of (10)-(16) are nonlinear with a square root operation, which is quite complex to solve by real-time controller directly. In addition, the equations (11)-(16) contain electrical angular velocity that requires real-time measurements, which increases the difficulty of solving equations.

2) The parameters in the equations cannot remain constant. When the magnetic saturation and cross saturation is significant, the inductance $L_{\mathrm{d}}$ and $L_{\mathrm{q}}$ will decrease with the increase of the dq-axis currents. The voltage constraints ignore the effect of resistance, which also affects the control accuracy, which will be further discussed in Section IV.

3) The solutions of these equations can be listed in advance in a pre-made table; however, considering inductance variation and resistance variation, these tables tend to be huge because it is necessary to create many separate tables.

\section{The Proposed NeWton-RAPHSON SEARCHING METHOD FOR DIFFERENT OPERATING MODES}

The second-order $\mathrm{N}-\mathrm{R}$ method is a fast convergence procedure to solve nonlinear equations $f(x, y)=0$ and $g(x, y)=0$, in our particular application, where $x$ is $i_{d}^{*}$ and $y$ is $i_{q}^{*}$ :

$$
\left\{\begin{array}{l}
z_{1}=f(x, y)=0 \\
z_{2}=g(x, y)=0
\end{array}\right.
$$

Equation (17) is our target function to find a value of $x, y$. Assuming that function (17) is continuous and there exists a continuous second-order partial derivative in the neighborhood at the point $\left(x_{0}, y_{0}\right),(17)$ can be expanded into Taylor series in (18) and equation (19) is the Jacobian matrix of (17):

$$
\begin{gathered}
\left\{\begin{array}{l}
f\left(x_{0}+\Delta x, y_{0}+\Delta y\right) \approx f\left(x_{0}, y_{0}\right)+\left.\Delta x f_{x}\right|_{x=x_{0}}+\left.\Delta y f_{y}\right|_{y=y_{0}} \\
g\left(x_{0}+\Delta x, y_{0}+\Delta y\right) \approx g\left(x_{0}, y_{0}\right)+\left.\Delta x g_{x}\right|_{x=x_{0}}+\left.\Delta y g_{y}\right|_{y=y_{0}}
\end{array}\right. \\
J=\left[\begin{array}{ll}
\frac{\partial f(x, y)}{\partial x} & \frac{\partial f(x, y)}{\partial y} \\
\frac{\partial g(x, y)}{\partial x} & \frac{\partial g(x, y)}{\partial y}
\end{array}\right]=\left[\begin{array}{ll}
f_{x}(x, y) & f_{y}(x, y) \\
g_{x}(x, y) & g_{y}(x, y)
\end{array}\right] \stackrel{\text { defined }}{\longrightarrow}\left[\begin{array}{cc}
f_{x} & f_{y} \\
g_{x} & g_{y}
\end{array}\right]
\end{gathered}
$$

Substituting $\Delta x=x_{k+1}-x_{k}, \Delta y=y_{k+1}-y_{k}, x_{0}=x_{k}$ and $y_{0}=y_{k}$ into (18), which the solutions in (17) can be expressed as (20) in iterative form:

$$
\left[\begin{array}{l}
x_{k+1} \\
y_{k+1}
\end{array}\right]=\left[\begin{array}{l}
x_{k} \\
y_{k}
\end{array}\right]-\left.J^{-1}\right|_{x=x_{k}, y=y_{k}}\left[\begin{array}{l}
f\left(x_{k}, y_{k}\right) \\
g\left(x_{k}, y_{k}\right)
\end{array}\right]
$$

If the condition (21) is satisfied

$$
g_{x}\left(x_{k}, y_{k}\right) f_{y}\left(x_{k}, y_{k}\right)-f_{x}\left(x_{k}, y_{k}\right) g_{y}\left(x_{k}, y_{k}\right) \neq 0
$$


When the inverse Jacobian matrix is substituted into (20), a second order N-R iterative form can be listed as (22):

$$
\left\{\begin{array}{l}
x_{k+1}=x_{k}+\frac{f\left(x_{k}, y_{k}\right) g_{y}\left(x_{k}, y_{k}\right)-g\left(x_{k}, y_{k}\right) f_{y}\left(x_{k}, y_{k}\right)}{g_{x}\left(x_{k}, y_{k}\right) f_{y}\left(x_{k}, y_{k}\right)-f_{x}\left(x_{k}, y_{k}\right) g_{y}\left(x_{k}, y_{k}\right)} \\
y_{k+1}=y_{k}+\frac{g\left(x_{k}, y_{k}\right) f_{x}\left(x_{k}, y_{k}\right)-f\left(x_{k}, y_{k}\right) g_{x}\left(x_{k}, y_{k}\right)}{g_{x}\left(x_{k}, y_{k}\right) f_{y}\left(x_{k}, y_{k}\right)-f_{x}\left(x_{k}, y_{k}\right) g_{y}\left(x_{k}, y_{k}\right)}
\end{array}\right.
$$

Where $x_{k+1}$ and $y_{k+1}\left(i_{d k+1}^{*}\right.$ and $\left.i_{q k+1}^{*}\right)$ are the new estimate of $x$ and $y, x_{k}$ and $y_{k}\left(i_{d k}^{*}\right.$ and $\left.i_{q k}^{*}\right)$ are the previous estimate of $x$ and $y\left(i_{d}^{*}\right.$ and $\left.i_{q}^{*}\right)$ respectively, $f\left(x_{k}, y_{k}\right)$ and $g\left(x_{k}, y_{k}\right)\left(f\left(i_{d k}^{*}, i_{q k}^{*}\right)\right.$ and $\left.g\left(i_{d k}^{*}, i_{q k}^{*}\right)\right)$ are the target functions using $x_{k}$ and $y_{k}\left(i_{d k}^{*}\right.$ and $i_{q k}^{*}$ ) ( in most cases, $f\left(x_{k}, y_{k}\right) \neq 0$ and $g\left(x_{k}, y_{k}\right) \neq 0$ because $x_{k}$ is not the correct solution). $k$ is an integer iteration index that starts with 1 . The iterative procedure starts by substituting a first guess $x(0)$ and $y(0)$ into (22) to get a second estimate. This second estimate is then substituted into (22) to get a third estimate. This process is repeated until the geometric distance of the two iterations results are very small ( $E$ is defined as current setting precision discussed in Section V):

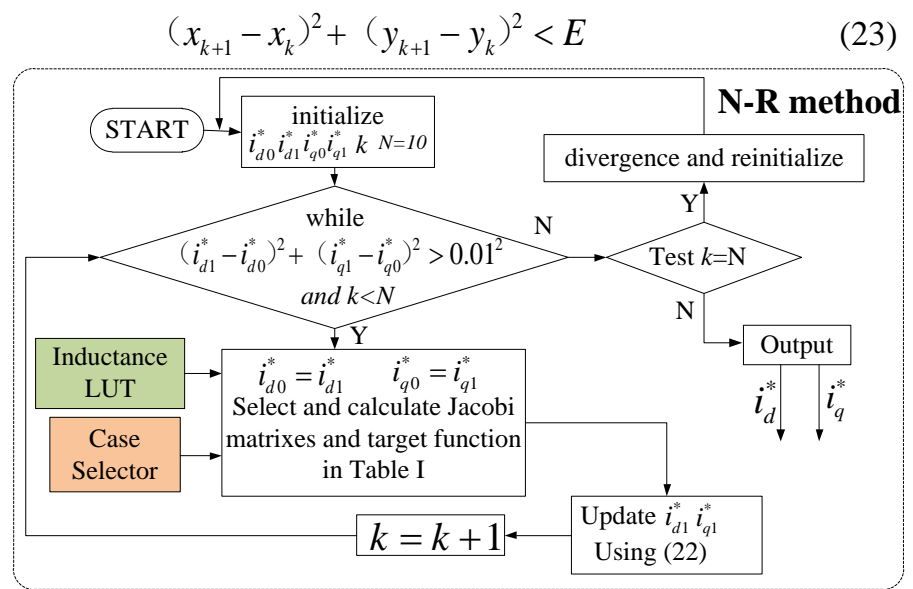

Fig.3 N-R method algorithm flow chart

The N-R algorithm flow chart is shown in Fig.3. The initial value for the first guess is set at first. $N$ represents the maximum number of iterations. The Jacobian matrix and the initial target function values $f\left(i_{\mathrm{d} 0}, i_{\mathrm{q} 0}\right)$ and $g\left(i_{\mathrm{d} 0}, i_{\mathrm{q} 0}\right)$ are used for the N-R iterative algorithm. Then $i_{\mathrm{d} 1}$ and $i_{\mathrm{q} 1}$ are update using (22). The iterative process are repeated until the error reaches a small value (i.e. minor than $0.01^{2}$ ), the current set-points rapidly converge to the optimal values. If the maximum number of iterations $N$ is exceeded, equation (22) is not converging and the searching algorithm has to be re-initialized.

According to four different branches shown in Fig.3, the N$\mathrm{R}$ searching method uses different target functions and Jacobian matrices in Table I to obtain the optimal current set-points. The proposed method is capable of considering the magnetic saturation and the resistive voltage drop as it will be later shown in the Section IV.

\section{The InfLuence of the Resistive Voltage Drop AND MAGNETIC SATURATION}

\section{A. Magnetic Saturation and Cross Saturation}

In most torque control applications, accurate inductance information is required for torque estimation and for an optimal current set-points selection. However, due to the magnetic saturation, the inductances vary nonlinearly depending on the current. In Fig.4, five measured dq-axis inductance values acquired by static inductance experiments discussed in [30][31] are compared with FEA results.

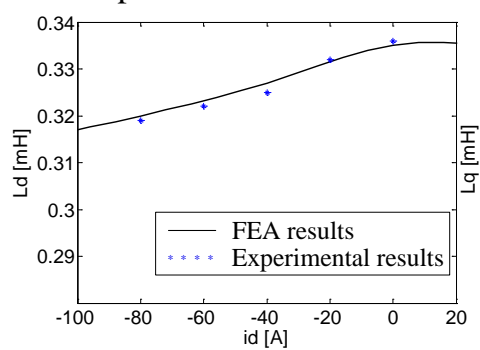

(a)

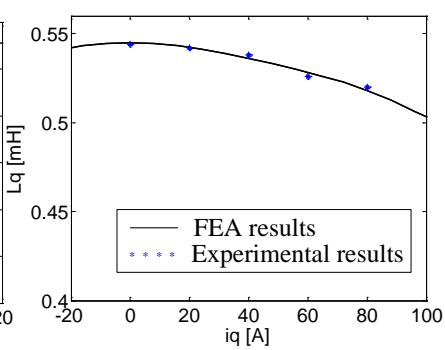

(b)
Fig.4 Experimental results compared with FEA results (a)d-axis inductance (b)q-axis inductance

TABLE I

TARGET FUNCTIONS AND JACOBI MATRICES FOR DIFFERENT OPERATING MODES (DQ-AXIS INDUCTANCES ARE COMING FROM ID AND IQ LUTS) Target function for MTPA, MC, FW, MTPV Jacobi matrix

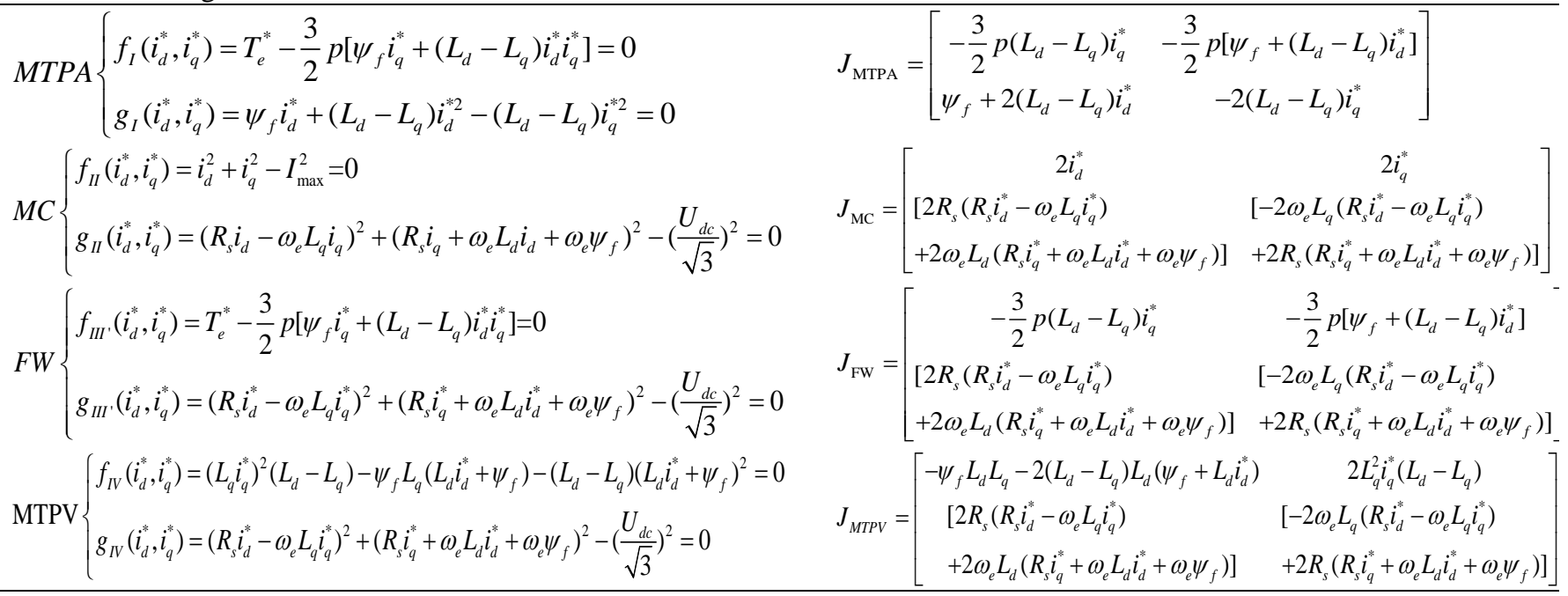


It is quite difficult and complicate to give an analytic relationship to describe both magnetic saturation and crosssaturation directly, so in order to reduce measurement repetition, a small table with averaged values from experimental measurements and FEA results is used in practice. The size of original tables is $11 \times 11$ shown in Fig.6(a).

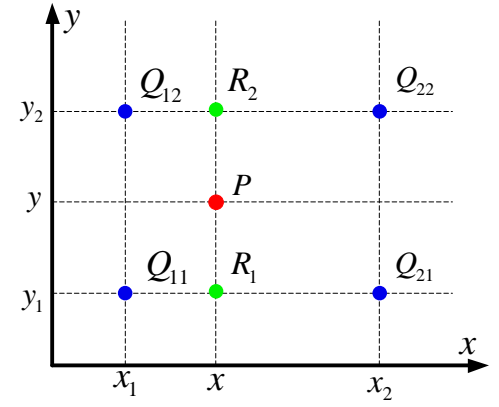

Fig. 5 sample points relationship for second-order bilinear interpolation method
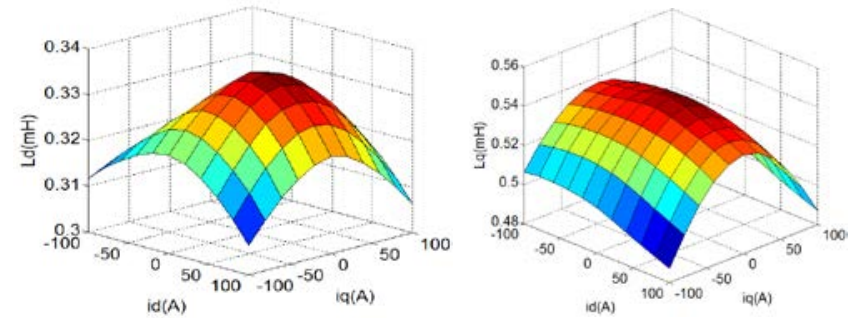

(a)
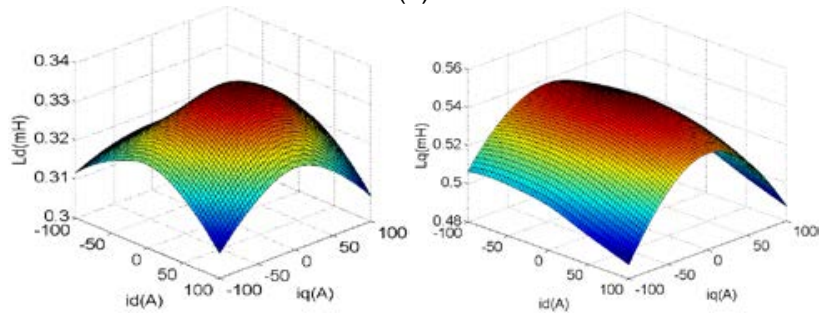

(b)

Fig.6 Expansion of the inductance data table (a)dq-axis inductance LUT without using SBIM (b)dq-axis inductance LUT using SBIM

In order to reduce the execution time discussed in Section VI, the second-order bilinear interpolation method (SBIM) is utilized to expand a small inductance tables to a larger one. In Fig.5, the blue points are four known points listed as: $\mathrm{Q}_{11}=f$ $\left(x_{1}, y_{1}\right) ., \mathrm{Q}_{12}=f\left(x_{1}, y_{2}\right), \mathrm{Q}_{21}=f\left(x_{2}, y_{1}\right)$ and $\mathrm{Q}_{22}=f\left(x_{2}, y_{2}\right)$, and the blue points are one unknown point $\mathrm{P}$. If the value is required from the unknown function $f(x, y)$ at point P. The SBIM can be expressed in the following steps:

Step 1. Using linear interpolation in the $x$ direction

$$
\left\{\begin{array}{l}
f\left(\mathrm{R}_{1}\right) \approx \frac{x_{2}-x}{x_{2}-x_{1}} f\left(Q_{11}\right)+\frac{x-x_{1}}{x_{2}-x_{1}} f\left(Q_{21}\right) \\
f\left(\mathrm{R}_{2}\right) \approx \frac{x_{2}-x}{x_{2}-x_{1}} f\left(Q_{12}\right)+\frac{x-x_{1}}{x_{2}-x_{1}} f\left(Q_{22}\right)
\end{array}\right.
$$

Step 2. Using linear interpolation in the $y$ direction

$$
f(P) \approx \frac{y_{2}-y}{y_{2}-y_{1}} f\left(R_{1}\right)+\frac{y-y_{1}}{y_{2}-y_{1}} f\left(R_{2}\right)
$$

Step 3. The final unknown point $P$ is introduced as (26)

$$
\begin{aligned}
& f(x, y) \approx \frac{f\left(\mathrm{Q}_{11}\right)}{\left(x_{2}-x_{1}\right)\left(y_{2}-y_{1}\right)}\left(x_{2}-x\right)\left(y_{2}-y\right)+\frac{f\left(\mathrm{Q}_{21}\right)}{\left(x_{2}-x_{1}\right)\left(y_{2}-y_{1}\right)}\left(x-x_{1}\right)\left(y_{2}-y .\right. \\
& +\frac{f\left(\mathrm{Q}_{12}\right)}{\left(x_{2}-x_{1}\right)\left(y_{2}-y_{1}\right)}\left(x_{2}-x\right)\left(y-y_{1}\right)+\frac{f\left(\mathrm{Q}_{22}\right)}{\left(x_{2}-x_{1}\right)\left(y_{2}-y_{1}\right)}\left(x-x_{1}\right)\left(y-y_{1}\right)
\end{aligned}
$$

Expansion results of the inductance data table can be simulated, as shown in Fig.6(b).

$B$. The Influence of the Resistive Voltage Drop

If the stator resistive voltage drop is considered, the voltage equation (1) and (2) at steady state can be rewritten as:

$$
\left\{\begin{array}{l}
u_{d}=R_{s} i_{d}-\omega_{e} L_{q} i_{q} \\
u_{q}=R_{s} i_{q}+\omega_{e} L_{d} i_{d}+\omega_{e} \psi_{f}
\end{array}\right.
$$

Noting that the temperature variation was negligible during the experiments presented in Section VI, the resistance is assumed to be constant. Substituting (27) into (4), the equation can be rewritten as (28), which indicates the voltage constraints trajectory accounting for the stator resistive voltage drop.

$$
\left(R_{s} i_{d}-\omega_{e} L_{q} i_{q}\right)^{2}+\left(R_{s} i_{q}+\omega_{e} L_{d} i_{d}+\omega_{e} \psi_{f}\right)^{2} \leq\left(\frac{U_{d c}}{\sqrt{3}}\right)^{2}
$$

The corrected curve for (28) forms a series of slant ellipses with speed, whose centers are moving with the increase of the motor speed. If the general equation of the ellipse is defined as

$$
A i_{d}^{2}+B i_{d} i_{q}+C i_{q}^{2}+D i_{d}+E i_{q}+F=0
$$

Equation (29) corresponds to (28) with the coefficients A, B, C, D, E and F described as:

$$
\begin{cases}A=R_{s}^{2}+\omega_{e}^{2} L_{d}^{2} & B=2 R_{s} \omega_{e}\left(L_{d}-L_{q}\right) \\ C=R_{s}^{2}+\omega_{e}^{2} L_{q}^{2} & D=2 R_{s} \omega_{e} \psi_{f} \\ E=-2 \omega_{e}^{2} L_{q} \psi_{f} & F=\omega_{e}^{2} \psi_{f}^{2}-\left(\frac{U_{d c}}{3}\right)^{2}\end{cases}
$$

As shown in Fig.7, the non-standard ellipse trajectory is composed of four elements: Center coordinates $\left(x_{\mathrm{c}}, y_{\mathrm{c}}\right)$, Semimajor axis a, Semi-minor axis b, and the inclination angle $\theta_{\mathrm{c}}$, which can be solved with the coefficients (31) :

$$
\left\{\begin{array}{l}
x_{c}=\frac{B E-2 C D}{4 A C-B^{2}}, \quad y_{c}=\frac{B D-2 A E}{4 A C-B^{2}}, \quad \theta_{c}=\frac{1}{2} \arctan \left(\frac{B}{A-C}\right) \\
a=2 \sqrt{\frac{-2 F}{A+C-\sqrt{B^{2}+\left(\frac{A-C}{F}\right)^{2}}}}, \quad b=2 \sqrt{\frac{-2 F}{A+C+\sqrt{B^{2}+\left(\frac{A-C}{F}\right)^{2}}}}
\end{array}\right.
$$

In conclusion, if the resistive voltage drop is considered, the intersection of the current constraint circle and the voltage constraint ellipse, marked as stars in Fig.7, should be moved from point $\mathrm{B}_{1}$ to point $\mathrm{B}_{2}$.

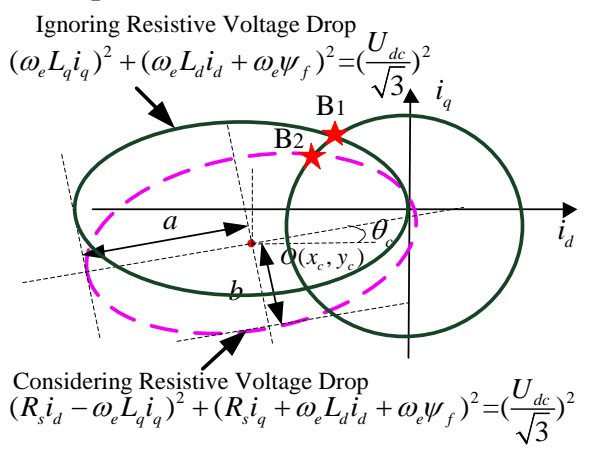

Fig.7 The locus of the voltage constraints ellipse (ignoring or considering the resistive voltage drop) 
Compared with the state-of-art, the N-R method combined with variable inductance LUT proposed in this paper has some advantages listed as follows:

1) The proposed N-R method is based on iterative operations, the intersections of complex nonlinear equations (10)-(16) involving current circle, voltage ellipse and torque hyperbola can be solved in real-time digital controllers.

2) According to different operating region, such as MTPA, MC, FW and MTPV region, the N-R searching method can switch different target functions and Jacobian matrices in Table I to obtain the optimal current set-points.

3) Thanks to the LUTs, the proposed N-R method can cope with the actual motor parameter variation, such as dq-axis inductance, resistance and permanent magnetic flux linkage. The controllability, accuracy improvement, and reduced computation burden achieved by using the LUTs will be demonstrated in Section VI.

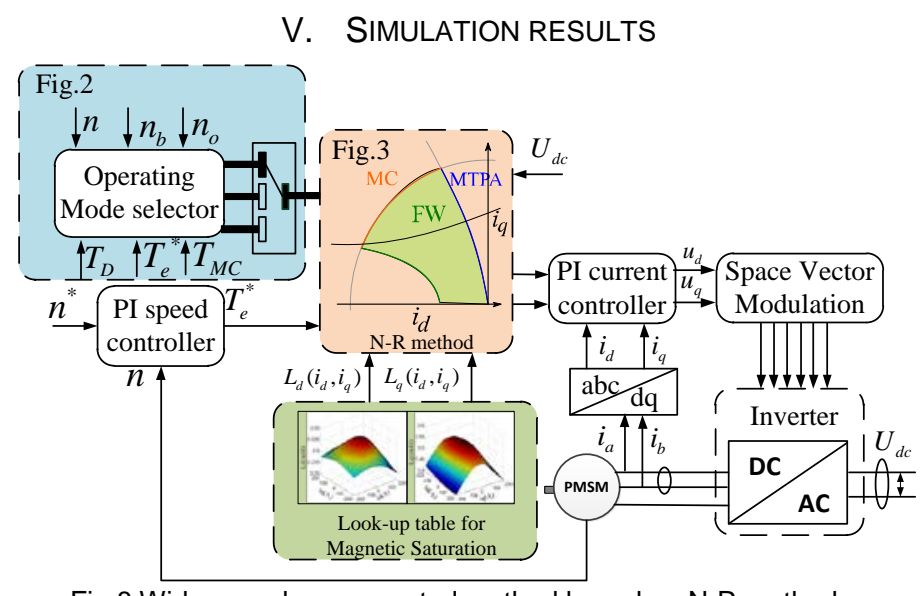

Fig. 8 Wide-speed range control method based on N-R method

In order to better verify the proposed control strategy in different operation modes shown in Fig.2, the control loop is constructed like the block diagram shown in Fig.8 and 8kW IPMSM parameters are presented in Table II. Noting that the MTPV locus does not intersect the MC circle, it will not be discussed in this Section V and Section VI.

TABLE II

\begin{tabular}{ccc} 
& \multicolumn{3}{c}{ IPMSM PARAMETERS } \\
\hline \hline IPMSM & VALUES & UNITS \\
\hline Rated torque & 32 & N.m \\
Base speed $\mathrm{n}_{\mathrm{b}}$ & 2400 & $\mathrm{rpm}$ \\
Max speed $\mathrm{n}_{\max }$ & 6000 & $\mathrm{rpm}$ \\
Boundary speed $\mathrm{n}_{0}$ & 2953 & $\mathrm{rpm}$ \\
Stator resistance & 0.1 & $\Omega$ \\
PM flux linkage & 0.06722 & $\mathrm{~Wb}$ \\
Pole pairs & 4 & \\
\hline \hline
\end{tabular}

\section{A. The Whole Convergence Process for MTPA Mode}

Taking initial value $i_{\mathrm{d} 0} i_{\mathrm{q} 0}(-30 \mathrm{~A}, 20 \mathrm{~A})$ and $(-4 \mathrm{~A}, 12 \mathrm{~A})$ as the first guess, the iterative convergence process of the $\mathrm{N}-\mathrm{R}$ algorithm in MTPA mode is shown in Table III. Comparing the operation condition I and II, due to the magnetic saturation effect of the inductance, the inductance is going down with a larger given torque. Comparing the operation condition I and III, symbol $\mathrm{E}$ is defined as current setting precision in the equation (23). When $E$ is set to be $0.01^{2}$, three steps of iteration are required to reach the MTPA set-points (-16.20A, 75.78A). When $E$ is set to be $0.001^{2}$, it takes four steps of iteration to reach the MTPA set-points (-16.208A, 75.768A). In this case, the accuracy is increased as the cost of more resources occupied. In this particular work, according to current sensor $0.2 \mathrm{~A} / \mathrm{mV}$, the current setting precision $E$ is set to be $0.01^{2}$.

TABLE III

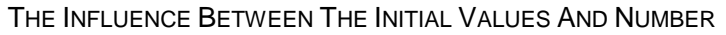
OF ITERATIONS IN MTPA MODE

\begin{tabular}{|c|c|c|}
\hline & $\begin{array}{l}\text { OPERATING } \\
\text { CONDITIONS }\end{array}$ & $\begin{array}{c}\text { CONVERGENT PROCESS FOR ID AND IQ SET- } \\
\text { POINTS }\end{array}$ \\
\hline \multirow{2}{*}{ I } & \multirow{2}{*}{$\begin{array}{c}\mathrm{Te}=32 \mathrm{~N} . \mathrm{m} \\
\mathrm{E}=0.01^{2} \\
\mathrm{Ld}=0.325 \mathrm{mH} \\
\mathrm{Lq}=0.521 \mathrm{mH}\end{array}$} & $\begin{array}{c}(-30,20) \rightarrow(-8.85,74.11) \rightarrow(-16.33,75.78) \rightarrow(- \\
16.20,75.77)\end{array}$ \\
\hline & & $\begin{array}{c}(-4,12) \rightarrow(-5.00,78.40) \rightarrow(-16.43,75.64) \rightarrow(- \\
16.19,75.78)\end{array}$ \\
\hline \multirow{2}{*}{ II } & \multirow{2}{*}{$\begin{array}{c}\mathrm{Te}=5 \mathrm{~N} \cdot \mathrm{m} \\
\mathrm{E}=0.01^{2} \\
\mathrm{Ld}=0.335 \mathrm{mH} \\
\mathrm{Lq}=0.544 \mathrm{mH}\end{array}$} & $\begin{array}{c}(-30,20) \rightarrow(-2.60,12.90) \rightarrow(-0.49,12.38) \rightarrow(- \\
0.47,12.38)\end{array}$ \\
\hline & & $(-4,12) \rightarrow(-0.51,12.37) \rightarrow(-0.47,12.38)$ \\
\hline \multirow[b]{2}{*}{ III } & \multirow{2}{*}{$\begin{array}{c}\mathrm{Te}=32 \mathrm{~N} . \mathrm{m} \\
\mathrm{E}=0.001^{2} \\
\mathrm{Ld}=0.325 \mathrm{mH} \\
\mathrm{Lq}=0.521 \mathrm{mH}\end{array}$} & $\begin{aligned}(-30,20) & \rightarrow(-8.854,74.103) \rightarrow(-16,333.75 .776) \\
& \rightarrow(-16.208,75.768)\end{aligned}$ \\
\hline & & $\begin{array}{c}(-4,12) \rightarrow(-4.998,78.396) \rightarrow(-16.433,75.639) \rightarrow(- \\
16.210,75.777) \rightarrow(-16.208,75.769)\end{array}$ \\
\hline \multirow{2}{*}{ IV } & \multirow{2}{*}{$\begin{array}{c}\mathrm{Te}=5 \mathrm{~N} . \mathrm{m} \\
\mathrm{E}=0.001^{2} \\
\mathrm{Ld}=0.335 \mathrm{mH} \\
\mathrm{Lq}=0.544 \mathrm{mH}\end{array}$} & $\begin{array}{c}(-30,20) \rightarrow(-2.601,12.896) \rightarrow(-0.487,12.382) \\
\rightarrow(-0.474,12.379)\end{array}$ \\
\hline & & $(-4,12) \rightarrow(-0.511,12.374) \rightarrow(-0.474,12.379)$ \\
\hline
\end{tabular}

\section{B. Simulation Results For Different Operation Regions}

Fig.9(a) corresponds to Fig.1(a) for the algorithm branch I, the speed set-points is set to be 500rpm less than the base speed 2400rpm. The IPMSM is ramping from 0rpm to 500rpm at max torque $32 \mathrm{~N} . \mathrm{m}$, which corresponds to point A in dq-axis current plane and then go to steady state at no load, which corresponds to point $\mathrm{L}_{0}$. The speed command is then stepped to $1000 \mathrm{rpm}$, the IPMSM is ramping to point $\mathrm{A}$ and again settles down at point $\mathrm{L}_{0}$. If the load torque is added at $1 \mathrm{~s}$, the operating point is moving from point $\mathrm{L}_{0}$ to point $\mathrm{C}$ along MTPA curve and balance at $10 \mathrm{~N}$.m finally.

Fig.9(b) corresponds to Fig.1(a)(b)(c)(d) for the algorithm branch II, the speed command $n^{*}$ is set to be 2800rpm (between base speed $n_{b}$ 2400rpm and $n_{o}$ 2953rpm). IPMSM is ramping with max torque $32 \mathrm{~N} . \mathrm{m}$ at point A. When the measured speed $n$ is higher than 2400rpm, the operating mode selector switch to the MC region and the flux is weakened by increasing the daxis current set-points in the negative directions. As the measured speed reaches 2800rpm, the dq-axis current starts to settle down to point $\mathrm{L}_{\mathrm{o}}$ passing by point $\mathrm{D}$ along the voltage ellipses $n^{*}$. If the load torque is added at $1.15 \mathrm{~s}$, the operating point is moving from point $\mathrm{L}_{0}$ to point $\mathrm{E}$ along MTPA curve.

Fig.9(c) corresponds to Fig.1(a)(e)(f) for the algorithm branch III, the speed set-points is firstly set to be 1000rpm below the base speed, the IPMSM is ramping with max torque 32N.m at point A and balance to steady state. When the speed set-point $n^{*}$ steps to 3600rpm (higher than the boundary speed 
$\mathrm{n}_{0}$ 2953rpm), the d-axis current will decrease towards point $\mathrm{B}$ along the MC circle. When the measured speed $n$ reaches steady state at 3600rpm, the operating will go along the voltage ellipse towards point $\mathrm{L}_{0}$ and, as soon as the load torque is added at $1.2 \mathrm{~s}$, it will balance at point $\mathrm{G}$ with the final torque.

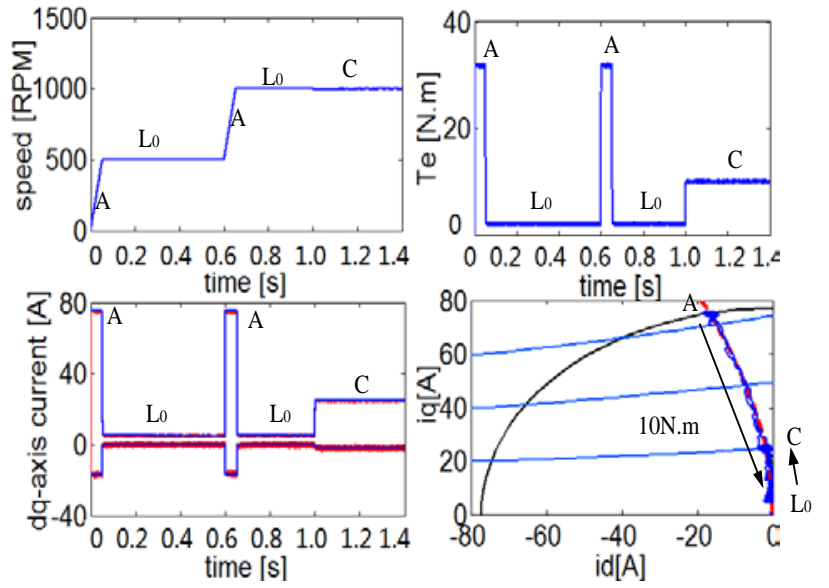

(a)

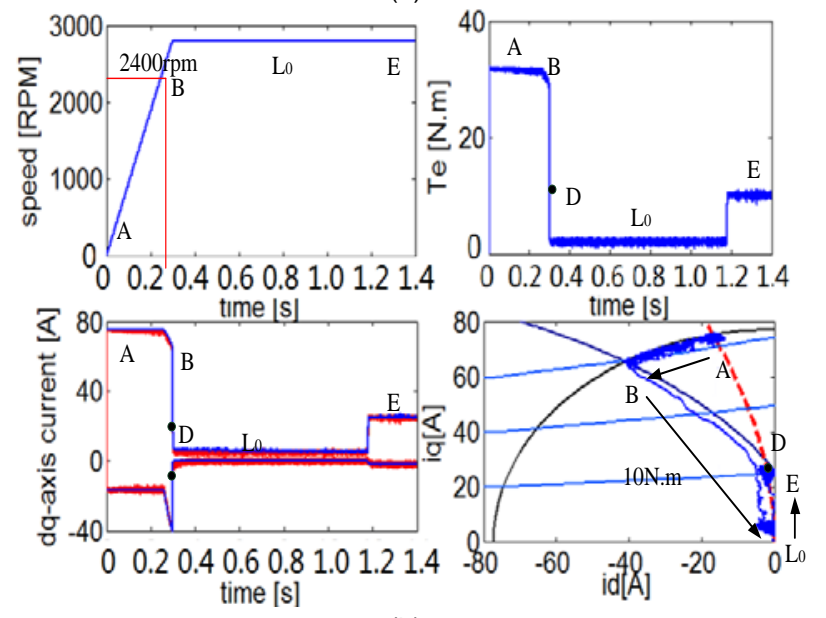

(b)
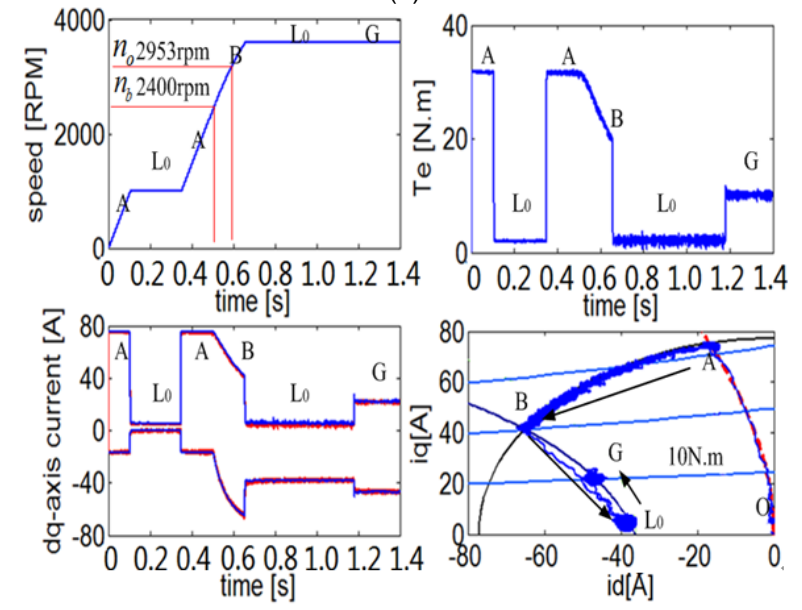

(c)

Fig.9 Simulation results with different operating modes (a) branch I (b) branch II (c) branch III

\section{EXPERIMENTAL RESULTS}

Several experimental tests are carried out to verify the effectiveness of the proposed method. The test bench is made up of a rated $8 \mathrm{~kW}$ target IPMSM (peak power $20 \mathrm{~kW}$ ) with resolver as position sensor, a $100 \mathrm{Nm}$ torque sensor, a 5:1 reducer and a magnetic powder brake as load, as shown in Fig.10. A DSP (Type:TMS320F28335) is used as core device for the controller. The inverter is a three-phase IGBT power module (Type: Infineon FS400R07A1E3), two current sensors, DC-link voltage sensor and some protection circuits. The switching frequency is $10 \mathrm{kHz}$ (Ts=100us).

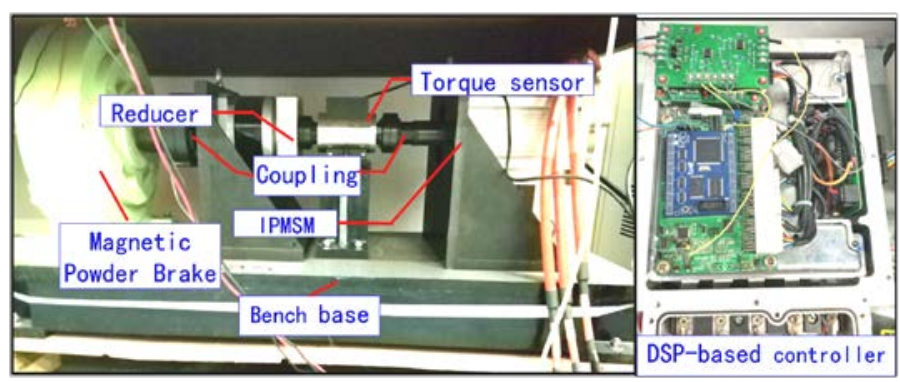

Fig.10 8kW IPMSM rig and DSP-based controller

\section{A. Experimental Results For Different Operation Regions}

The experimental results for testing MTPA region (branch I, Fig.1(a)) dealing with magnetic saturation are shown in Fig.11(a)(d). The initial speed set-points $\mathrm{n}^{*}$ in orange and the measured speed $n$ in pink in Fig.11(a) are 500rpm. When the speed set-points step to 1000rpm ( $\left.\leq n_{b}\right)$, the dq-axis current set-points are -16A and 76.8A (at max torque 32N.m). The dqaxis inductance goes saturation at $0.326 \mathrm{mH}$ (decline $2.7 \%$ ) and $0.522 \mathrm{mH}$ (decline $4.2 \%$ ), respectively, due to the high starting current. After reaching 1000rpm, the dq-axis inductance will be $0.334 \mathrm{mH}$ and $0.545 \mathrm{mH}$, quite close to the rated inductance value ( $L_{\mathrm{d}}=0.335 \mathrm{mH}$ and $\left.L_{\mathrm{q}}=0.545 \mathrm{mH}\right)$. When the load torque is added to $15 \mathrm{~N}$.m, the dq-axis current set-points are $-4.8 \mathrm{~A}$ and $38 \mathrm{~A}$, while the dq-axis inductance will be $0.332 \mathrm{mH}$ (decline $0.9 \%$ ) and $0.537 \mathrm{mH}$ (decline $1.5 \%$ ).

The experiment results for testing branch II (corresponding to Fig.1(a)(b)(c)(d)) are shown in Fig.11(b)(e). The initial speed is 1500rpm at steady state. After the speed set-points step to 2700rpm $\left(\mathrm{n}_{\mathrm{b}}<\mathrm{n} \leq \mathrm{n}_{\mathrm{o}}\right)$, IPMSM began to accelerate and the given torque (max torque $32 \mathrm{~N}$.m) is assigned by N-R searching method to obtain dq-axis current set-points at -16A and 76.8A (point A). When the speed increases higher than the base speed 2400rpm(switch to MC region), deeper flux-weakening d-axis current is required to shift the point from $\mathrm{A}$ to $\mathrm{B}$ along the current circle. Later on, when the speed reaches the speed setpoints, the reference torques finally balance with a load torque $5 \mathrm{~N}$.m along the voltage ellipse in FW region and finally balance on MTPA curve (point E).

The experiment results for testing branch III (corresponding to Fig.1(a)(e)(f)) are shown in in Fig.11(c)(f). The measured speed $n$ is 2000rpm at steady state. After the speed set-points steps to 3600rpm ( $\left.n>n_{o}\right)$, IPMSM began to enter the speed transition. The given torque (at max torque $32 \mathrm{~N} . \mathrm{m}$ ) is assigned by $\mathrm{N}-\mathrm{R}$ searching method to $-16 \mathrm{~A}$ and $76.8 \mathrm{~A}$ at point $\mathrm{A}$. When the speed increases higher than the base speed 2400rpm, deeper flux-weakening is required to limit voltage, shifting the point 
from A to B along the current constraints circle. Later on, the speed is approaching the speed set-points $3600 \mathrm{rpm}$, the reference torques finally balance with a load torque 5 N.m along

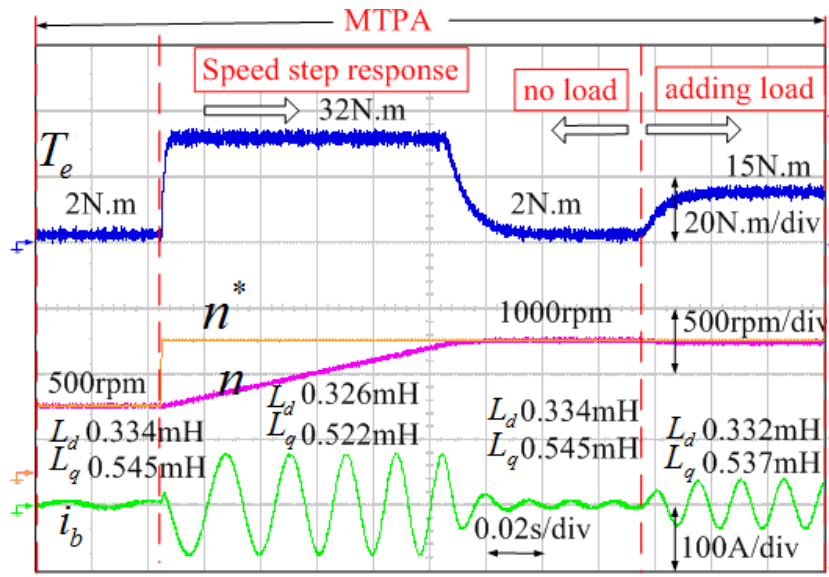

(a) branch I

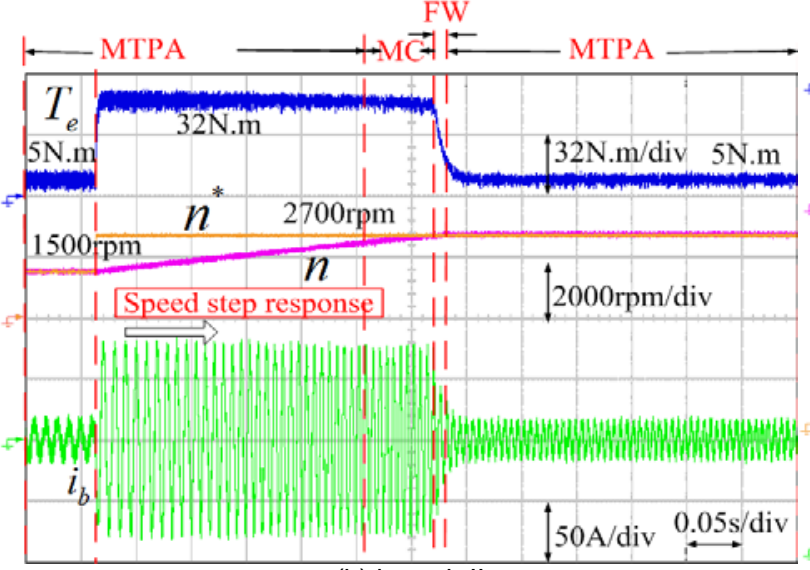

(b) branch II

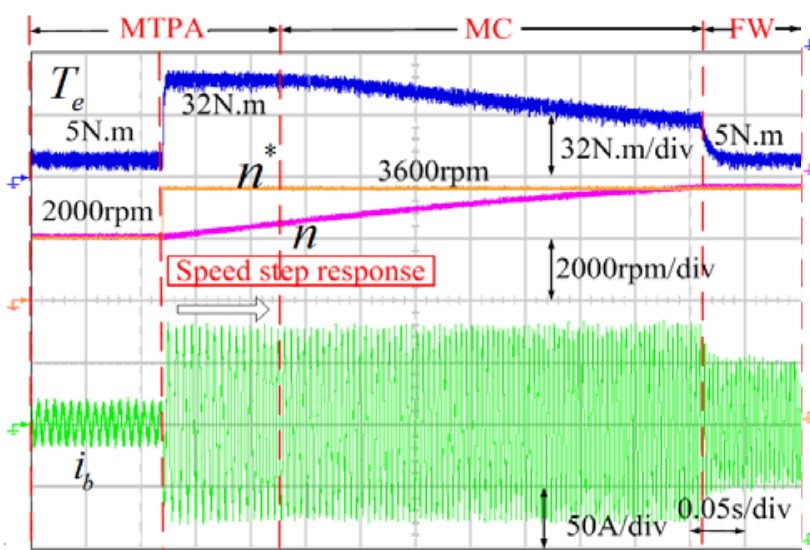

(c) branch III

Fig.11 The experimental results for different branches: waveform of torque , speed set-points, speed measurement and phase B current(a) branch I (b) branch II (c) branch III; waveform of dq-axis current set-points and measurement (d) branch I (e) branch II (f) branch III

\section{B. Experimental Results For Control Accuracy And Computation Burden}

Fig.12 shows the proposed method dealing with parameter mismatch in MC region as discussed in Section IV. At the initial steady state I, the IPMSM is spinning at the speed of 3000rpm. Fig. 12 shows the large q-axis current error when the fixed values of $L_{\mathrm{d}}=0.335 \mathrm{mH}, L_{\mathrm{q}}=0.545 \mathrm{mH}$ and $R_{\mathrm{s}}=0 \Omega$ are used. The q-axis current measurement differs significantly from the the voltage constraints ellipse towards point G.

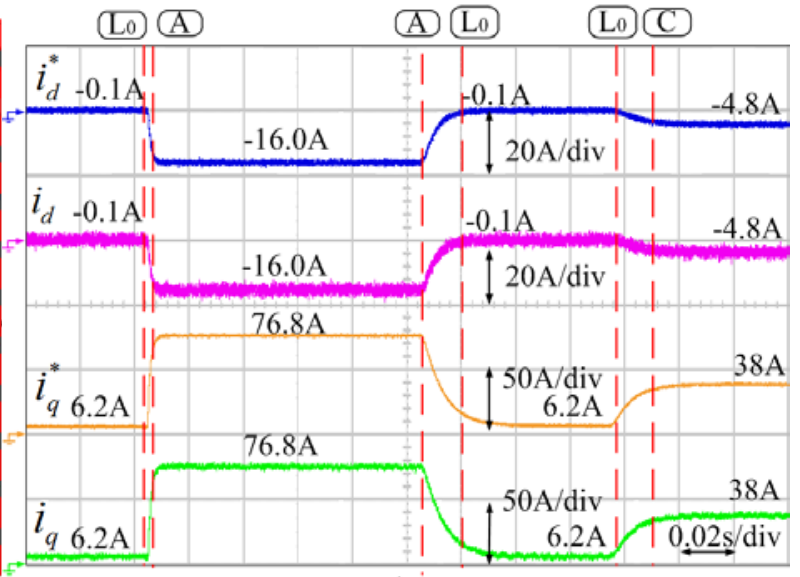

(d) branch I

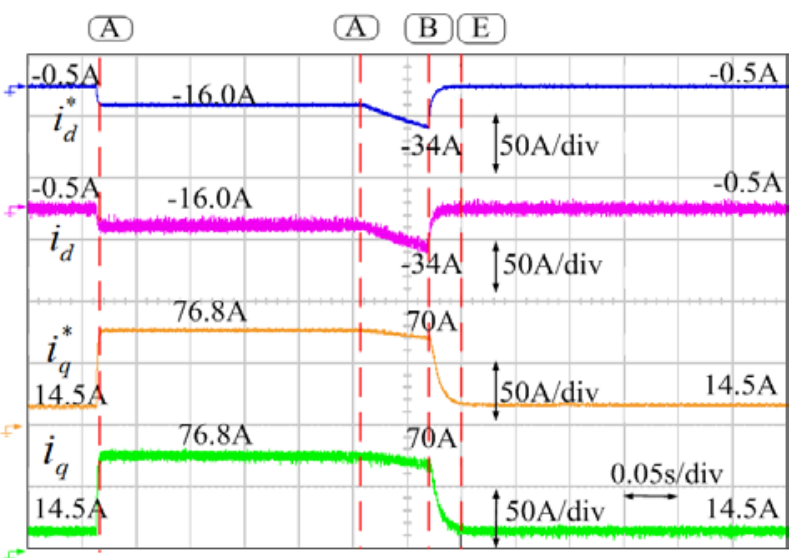

(e) branch II

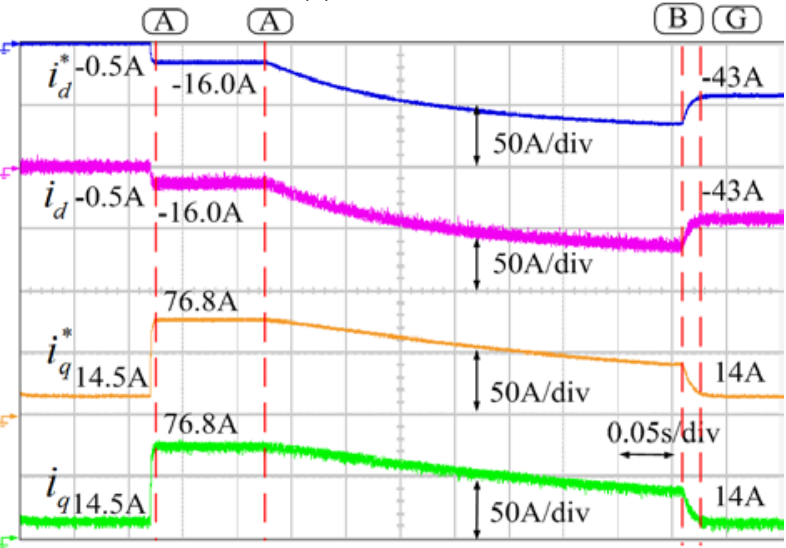

(f) branch III current set-points, due to large mismatch of the motor parameters. Therefore, the performance of the IPMSM is degrading. When the variable parameters have been compensated by LUT later on in steady state II, the q-axis current set-points control errors reduce from about $20 \mathrm{~A}$ to about $0 \mathrm{~A}$. The main reason is that the corrected voltage ellipse considering the resistive voltage drop in the dq-axis current plane forms a series of slant ellipses. The resistive voltage drop forces the current set-points to move from point $B_{1}$ to point $B_{2}$ 
corresponding to Fig.7, discussed in section IV. This proves the necessity of updating $L_{\mathrm{d}}$ and $L_{\mathrm{q}}$ and considering the influence for resistive voltage drop.

In order to test the execution time of different methods, the IO pin in the DSP is set to be high before the proposed method and reset it to low after the function has executed, as shown in Fig.13(a). The duration of the pulse can be measured in the oscilloscope, shown as histogram in Fig.13(b). In the method 1, the N-R method is applied with dq-axis inductance matrices (size:11×11) and expanded by SBIM took least computation time 45.85us. In method 2, the second-order PA method is used for the inductance curve-fitting mentioned in [23] and [24], the solution in Table I occupies 56.2us. In method 3, the N-R method needs 65.8us combined with $61 \times 61$ inductance matrices. In method 4 , the square root operation is saved in advance using premade tables and $61 \times 61$ inductance matrices are applied for parameter compensation. Comparing method 3 and method 4, the proposed N-R method occupied 18.1us less resource than square root operation, since the proposed N-R method is based only on iteration and selection operations. Comparing method 1 and method 3, the SBIM can reduce the size of LUTs and 20us execution time margin is saved.

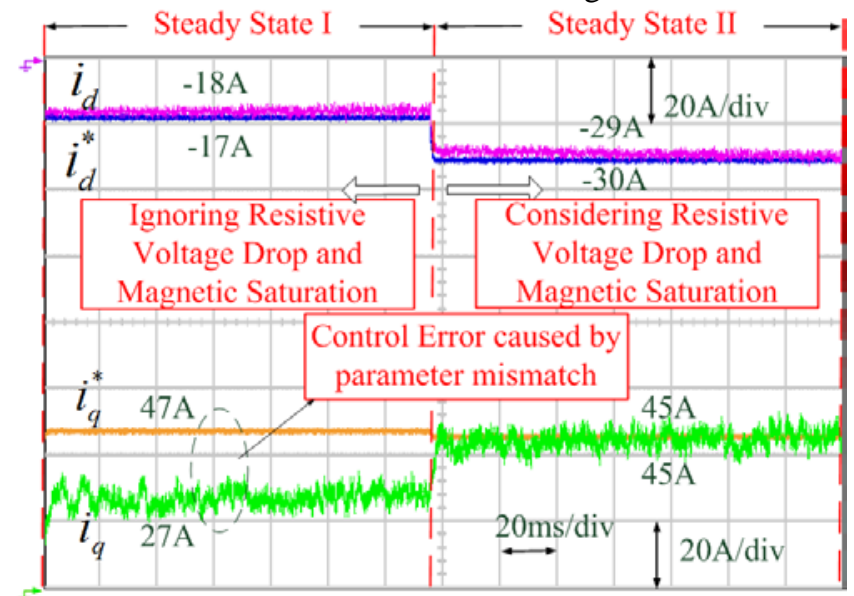

Fig.12 Experiment results with parameter mismatch at 3000rpm

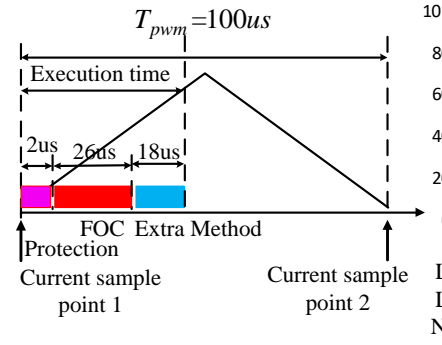

(a)

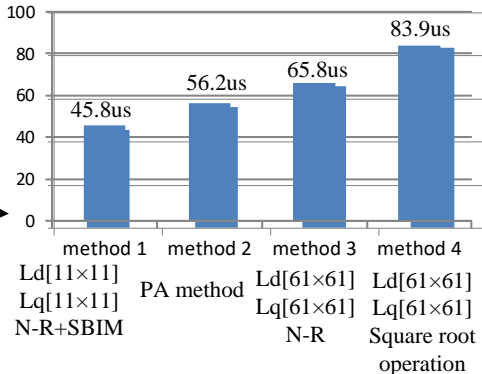

(b)
Fig.13 Experiment results for execution time (a) in PWM period (b) dealing with four different methods

\section{CONCLUSION}

In this paper, the operating modes for IPMSM are divided into MTPA region, MC region, FW region and MTPV region. The target non-linear functions for optimal current set-points are presented. In order to get more accurate solution, N-R feedforward searching method is proposed to find the optimal current set-points in iterative forms. It has been highlighted that neglecting the resistive voltage drop and magnetic saturation leads the actual current trajectory to deviate from the optimal one, resulting in reduced accuracy. Therefore, LUT combined with second-order bilinear interpolation method is used for variable parameters compensation.

The simulations and experimental results are demonstrating the validity and accuracy of the proposed searching method. This has been verified in various operation cases and also the case dealing with parameter mismatch. The applied method has been proved to improve the control accuracy of IPM machines in wide-speed range, while reducing the computation burden at the same time.

\section{REFERENCES}

[1] X. Liu, H. Chen, J. Zhao, and A. Belahcen, "Research on the performances and parameters of interior PMSM used for electric vehicles”, IEEE Trans. Ind. Electron. vol. 63, no. 6, pp. 3533-3545, Feb. 2016.

[2] Lu D, Kar N C . "A review of flux-weakening control in permanent magnet synchronous machines”, IEEE Veh. Power Propul. Conf. (VPPC). Sept. 2010.

[3] Huang S, Chen Z, Huang K. "Maximum torque per ampere and fluxweakening control for PMSM based on curve fitting”, IEEE Veh. Power Propul. Conf. (VPPC). Sept. 2010.

[4] Inoue T, Inoue Y, Morimoto S. "Mathematical Model for MTPA Control of Permanent-Magnet Synchronous Motor in Stator Flux Linkage Synchronous Frame”, IEEE Trans. Ind. Appl. vol.51, no.5, pp. 3620 3628. Sept. 2015.

[5] Kim S, Yoon Y D, Sul S K. "Maximum torque per ampere (MTPA) control of an IPM machine based on signal injection considering inductance saturation”, IEEE Trans. Power Electron. vol.28, no.1, pp. 488-497. Apr. 2013

[6] Bolognani S, Petrella R, Prearo A. "Automatic tracking of MTPA trajectory in IPM motor drives based on AC current injection”, IEEE Trans. Ind. Appl. vol.47, no.1, pp. 105-114. Nov. 2011

[7] Lai C, Feng G, Tjong J. "Direct Calculation of Maximum-Torque-perAmpere Angle for Interior PMSM Control Using Measured Speed Harmonic", IEEE Trans. Power Electron. vol.33, no.11, pp. 9744 - 9752. Nov. 2018.

[8] Liu G, Wang J, Zhao W. "A Novel MTPA Control Strategy for IPMSM Drives by Space Vector Signal Injection”, IEEE Trans. Ind. Electron. vol.64, no.12, pp.9243-9252. Jun. 2017

[9] Lemmens J, Vanassche P, Driesen J. "PMSM drive current and voltage limiting as a constraint optimal control problem”, IEEE Trans. Emerging Sel. Topics Power Electron. vol.3, no.2, pp.326-338. Apr.2015

[10] Lai C, Feng G, Mukherjee K. "Maximum Torque per Ampere Control for IPMSM Using Gradient Descent Algorithm based on Measured Speed Harmonics”, IEEE Trans. Ind. Informat. vol.14, no.4, pp.1424-1435. Oct. 2017.

[11] Preindl M , Bolognani S . "Optimal State Reference Computation With Constrained MTPA Criterion for PM Motor Drives”, IEEE Trans. Power Electron., 2015, vol.30, no.8, pp.4524-4535. Aug. 2015

[12] Tursini M, Chiricozzi E, Petrella R. "Feedforward flux-weakening control of surface-mounted permanent-magnet synchronous motors accounting for resistive voltage drop", IEEE Trans. Ind. Electron. vol.57, no. 1, pp. 440-448. Oct.2010

[13] Tursini M, Chiricozzi E, Petrella R . "Flux-weakening control of surface mounted PM synchronous motors accounting for resistive voltage drop", IEEE 18th Int. Conf. on Electr. Mac. (ICEM), Sept. 2008.

[14] Liu H, Zhu Z Q, Mohamed E. "Flux-weakening control of nonsalient pole PMSM having large winding inductance, accounting for resistive voltage drop and inverter nonlinearities”, IEEE Trans. Power Electron. vol.27, no.2, pp. 942-952.Jun. 2012

[15] Kwon T S, Sul S K. "Novel antiwindup of a current regulator of a surfacemounted permanent-magnet motor for flux-weakening control”, IEEE Trans. Ind. Appl. vol.42, no.5, pp.1293-1300. Sept. 2006

[16] Kwon Y C, Kim S, Sul S K. "Voltage feedback current control scheme for improved transient performance of permanent magnet synchronous 
machine drives”, IEEE Trans. Ind. Electron. vol.59, no.9, pp.3373-3382. Dec. 2012

[17] Preindl M, Bolognani S. "Model predictive direct torque control with finite control set for PMSM drive systems, part 2: field weakening operation”, IEEE Trans. Ind. Informat. vol.9, no.2, pp.648-657. Sept. 2013

[18] Maurice F , Leopold S , Maria D. "MTPV Flux Weakening Strategy for PMSM High Speed Drive”, IEEE Trans. Ind. Appl. vol.54, no.6, pp. 6081 - 6089. Dec. 2018

[19] Pellegrino G, Armando E, Guglielmi P. "Direct-Flux Vector Control of IPM Motor Drives in the Maximum Torque Per Voltage Speed Range", IEEE Trans. Ind. Electron. vol.59, no.10, pp.3780-3788. Oct. 2012

[20] Eldeeb H, Hackl C M, Horlbeck L. "A unified theory for optimal feedforward torque control of anisotropic synchronous machines”, Int. J. of Contr. vol.91, no.10, pp. 2273-2302. Jul. 2017.

[21] Jo C, Seol J Y, Ha I J. "Flux-weakening control of IPM motors with significant effect of magnetic saturation and stator resistance", IEEE Trans. Ind. Electron. vol.55, no.3, pp.1330-1340. Mar. 2008

[22] Lee J, Nam K, Choi S. "Loss-minimizing control of PMSM with the use of polynomial approximations", IEEE Trans. Power Electron. vol.24, no.4, pp. 1071-1082. Feb.2009

[23] Miao Y, Ge H, Preindl M. "MTPA Fitting and Torque Estimation Technique Based on a New Flux-Linkage Model for Interior-PermanentMagnet Synchronous Machines”, IEEE Trans. Ind. Appl. vol.53, no.6, pp. 5451-5460.Jun. 2017

[24] Rabiei A, Thiringer T, Alatalo M. "Improved maximum torque per ampere algorithm accounting for core saturation, cross-coupling effect, and temperature for a PMSM intended for vehicular applications”, IEEE Trans. Transp. Electr. vol.2, no.2, pp 150-159. Feb. 2016

[25] Jung S Y, Hong J, Nam K. "Current minimizing torque control of the IPMSM using Ferrari's method”, IEEE Trans. Power Electron. vol. 28, no.12, pp.5603-5617. Feb.2013

[26] Nalepa R, Orlowska-Kowalska T. "Optimum trajectory control of the current vector of a nonsalient-pole PMSM in the field-weakening region", IEEE Trans. Ind. Electron. vol.59, no.7: pp.2867-2876. Feb. 2012

[27] Liu K, Feng J , Guo S. "Identification of Flux Linkage Map of Permanent Magnet Synchronous Machines under Uncertain Circuit Resistance and Inverter Nonlinearity”, IEEE Trans. Ind. Electron. vol.14, no.2, pp. 556 568. Feb. 2018

[28] Sandre-Hernandez O, Morales-Caporal R , Rangel-Magdaleno J. "Parameter Identification of PMSMs Using Experimental Measurements and a PSO Algorithm”, IEEE Trans. Instrum. Meas. vol.64, no.8, pp.2146-2154. Aug. 2015

[29] Liu Z H , Wei H L , Zhong Q C. "Parameter estimation for VSI-Fed PMSM based on a dynamic PSO with learning strategies", IEEE Trans. Power Electron. vol.32, no.4, pp.3154 - 3165. Apr.2017

[30] Cavagnino, A, Vaschetto, S, Agamloh, E. "Practical considerations on the off-line measurements of PMSM and SyRM inductances". IEEE Energy Conver. Cong. and Expos. (ECCE), pp. 1175-1182. Oct.2017

[31] Kazerooni M, Kar N C. "Methods for determining the parameters and characteristics of PMSM". IEEE Int. Electr. Mach. \& Drives Conf. (IEMDC), pp. 955-960, May. 2011.

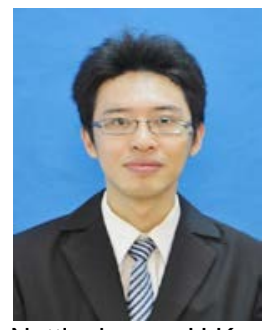

Shuo Wang (S'17-M'19) received the bachelor degree in automation from Hebei university of Technology in 2011, Tianjin, China, master degree in control science and engineering from Tianjin university in 2014, Tianjin, China, and $\mathrm{Ph} . \mathrm{D}$. degree in control science and engineering from Tongji University in 2019, Shanghai, China. From 2017 to 2018, he was a Visiting researcher with Power Electronics, Machines and Control Group (PEMC Group), University of Nottingham, Nottingham, U.K. His current research interests include high performance torque control, sensorless control and flux-weakening control used for permanent magnet synchronous machines, synchronous reluctance machines and permanent magnet-assisted synchronous reluctance machines.

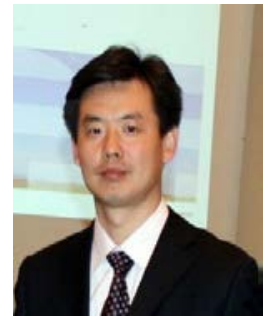

Jinsong Kang ( M'18) received the bachelor degree in electrical engineering from Shanghai Railway Institute, Shanghai, China, and the Ph.D. degree from Tongji University, Shanghai, in 1994 and 2003, respectively.

He became a Professor in the Department of Electrical Engineering, Tongji University, Shanghai, in 2011. His main research interests include the field of power electronics and drive control, including drive system applied in electric vehicles, traction systems and auxiliary power supply of mass transit vehicles.

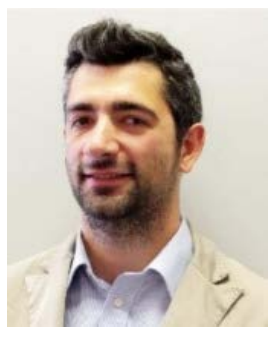

Michele Degano (M'15) received the Laurea degree in electrical engineering from the University of Trieste, Trieste, Italy, in 2011, and the Ph.D. degree in industrial engineering from the University of Padova, Padova, Italy, in 2015. During his doctoral studies, he cooperated with several local companies for the design of permanent-magnet machines. In 2015, he joined the Power Electronics, Machines and Control Group, The University of Nottingham, Nottingham, U.K., as a Research Fellow, where he is currently an Assistant Professor teaching advanced courses on electrical machines. His main research interests include design and optimization of permanent-magnet machines, reluctance and permanent magnet assisted synchronous reluctance motors through genetic optimization techniques, for automotive and aerospace applications, ranging from small to large power.

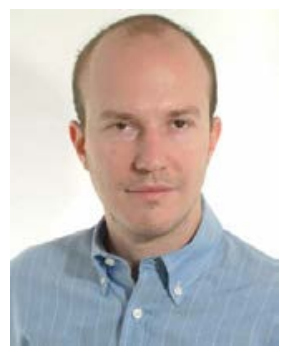

Alessandro Galassini (S'13-M'17) received the master's degree in mechatronic engineering from the University of Modena and Reggio Emilia, Reggio Emilia, Italy, in 2012, and the Ph.D. degree in power sharing for multi three phase electrical machines from the University of Nottingham, Nottingham, U.K., in 2017. He is currently a Researcher with the Power Electronics, Machines and Control Group, University of Nottingham. His research area is focused on control of electrical drives for future transportation systems.

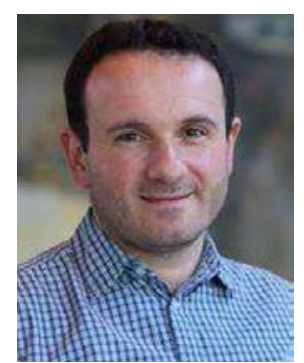

Chris Gerada (M'05-SM'14) received the Ph.D. degree in numerical modeling of electrical machines from The University of Nottingham, Nottingham, U.K., in 2005. He subsequently worked as a Researcher with the University of Nottingham on high performance electrical drives and on the design and modeling of electromagnetic actuators for aerospace applications. Since 2006, he has been the Project Manager of the GE Aviation Strategic Partnership. In 2008, he was appointed as a Lecturer in electrical machines; in 2011, as an Associate Professor; and in 2013, as a Professor at The University of Nottingham. His main research interests include the design and modeling of high-performance electric drives and machines.

Prof. Gerada serves as an Associate Editor of the IEEE transactions on industry applications and is the Chair of the IEEE Industrial Electronics Society Electrical Machines Committee. 